\title{
Microstimulation reveals opposing influences of prelimbic and infralimbic cortex on the expression of conditioned fear
}

\author{
Ivan Vidal-Gonzalez, ${ }^{1}$ Benjamín Vidal-Gonzalez, ${ }^{1}$ Scott L. Rauch, ${ }^{2}$ \\ and Gregory J. Quirk'1,3 \\ ${ }^{1}$ Department of Physiology, Ponce School of Medicine, Ponce, Puerto Rico 00732; ${ }^{2}$ Department of Psychiatry, Massachusetts \\ General Hospital and Harvard Medical School, Charlestown, Massachusetts 02129, USA
}

\begin{abstract}
Recent studies using lesion, infusion, and unit-recording techniques suggest that the infralimbic (IL) subregion of medial prefrontal cortex (mPFC) is necessary for the inhibition of conditioned fear following extinction. Brief microstimulation of IL paired with conditioned tones, designed to mimic neuronal tone responses, reduces the expression of conditioned fear to the tone. In the present study we used microstimulation to investigate the role of additional mPFC subregions: the prelimbic ( $\mathrm{PL})$, dorsal anterior cingulate (ACd), and medial precentral $(\mathrm{PrCm})$ cortices in the expression and extinction of conditioned fear. These are tone-responsive areas that have been implicated in both acquisition and extinction of conditioned fear. In contrast to IL, microstimulation of PL increased the expression of conditioned fear and prevented extinction. Microstimulation of ACd and $\operatorname{PrCm}$ had no effect. Under low-footshock conditions (to avoid ceiling levels of freezing), microstimulation of PL and IL had opposite effects, respectively increasing and decreasing freezing to the conditioned tone. We suggest that PL excites amygdala output and IL inhibits amygdala output, providing a mechanism for bidirectional modulation of fear expression.
\end{abstract}

Disorders of fear and anxiety such as post-traumatic stress disorder (PTSD) are thought to reflect deficits in emotional regulation. While the amygdala has long been considered a site of storage of conditioned fear memories, recent findings suggest that the medial prefrontal cortex (mPFC) regulates expression of amygdaladependent memories, especially following extinction (SotresBayon et al. 2004; Amat et al. 2005; Milad et al. 2005; Quirk et al. 2006). In auditory fear conditioning, rats with lesions of the infralimbic (IL) subregion of mPFC extinguish freezing responses within a session but spontaneously recover excessive freezing to the tone the following day, suggesting impaired recall of extinction (Quirk et al. 2000; Lebron et al. 2004). Consistent with lesion findings, the excitability of IL neurons is increased when rats are recalling extinction (Herry and Garcia 2002; Milad and Quirk 2002; Barrett et al. 2003). Tone responses of single IL neurons are larger $24 \mathrm{~h}$ after extinction training when rats are recalling extinction (Milad and Quirk 2002). These and other findings (Hugues et al. 2004; Santini et al. 2004; Burgos-Robles et al. 2005) suggest that increased activity in IL suppresses fear after extinction (Milad et al. 2006; Quirk et al. 2006).

In support of the IL-inhibitory hypothesis, pairing conditioned tones with microstimulation of IL reduced conditioned freezing (Milad and Quirk 2002; Milad et al. 2004). This effect was seen only when stimulation was delivered at tone onset, suggesting that tone-evoked activity in IL gates the excitability of downstream structures such as the amygdala (Rosenkranz et al. 2003; Pelletier and Paré 2004; Quirk et al. 2006). In addition to IL, other prefrontal subregions have been implicated in the acquisition and extinction of conditioned fear. A metabolic mapping study showed increased activity in the dorsal anterior cingulate (ACd) and medial precentral cortex (PrCm) during extinc-

\footnotetext{
${ }^{3}$ Corresponding author.

E-mail gjquirk@yahoo.com; fax: (787) 844-1980.

Article is online at http://www.learnmem.org/cgi/doi/10.1101//m.306106.
}

tion recall (Barrett et al. 2003), suggesting that IL may be part of a larger mPFC circuit that inhibits fear expression.

In contrast to the idea that the mPFC inhibits fear, investigators have reported conditioning-induced increases in neuronal tone responses in PL (prelimbic) (Baeg et al. 2001; Gilmartin and McEchron 2005), ACd (Peterson 1986), and PrCm (Yajeya et al. 1988), consistent with a role of these structures in augmenting fear expression. Thus, existing data disagree as to the role of these structures in fear learning. In the present study, we paired microstimulation of IL, PL, ACd, and PrCm with conditioned tones to determine the contribution of each subregion to the expression of conditioned fear. We asked two questions: (1) Does microstimulation of a given subregion alter the expression of fear to the tone? and (2) Does microstimulation facilitate or impair extinction learning?

\section{Results}

\section{Histology}

A total of 76 rats were tested. The photomicrograph in Figure 1A shows a representative electrode track in PL, and Figure 1B shows the placements of all stimulating electrodes. A total of 39 rats were stimulated in one of four mPFC subregions: PrCm, ACd, PL, or IL. To control for the effects of electrode implantation, 37 rats were implanted with stimulating electrodes in the corresponding regions, but were never stimulated (Unstim group). The $n$ for individual experiments are given in the figure legends.

\section{Microstimulation of $\mathrm{ACd}$ and $\operatorname{PrCm}$ has no effect on fear expression or extinction}

On Day 1, rats were fear-conditioned and treatment groups were matched for final conditioning level. On Day 2, all rats were exposed to partial extinction training consisting of eight tones. In the stimulated group, extinction tones were paired with microstimulation of either PrCm, ACd, or PL. The latency of stimu- 
A

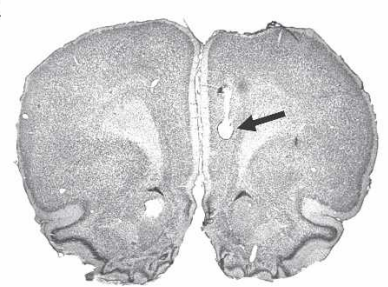

B
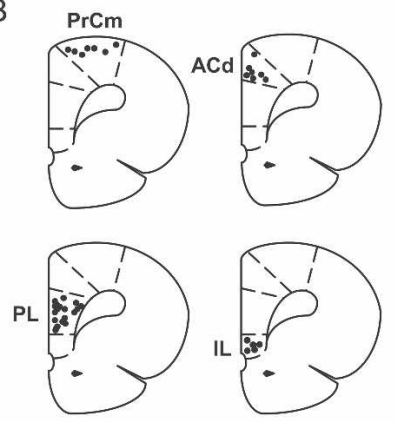

C

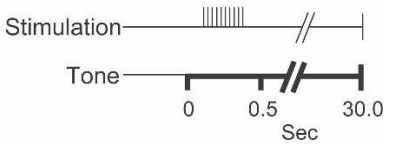

Figure 1. Placements of stimulating electrodes in different prefrontal subregions. (A) Photomicrograph showing the tip of a stimulating electrode in $\mathrm{PL}$ (arrow). (B) Coronal drawings (bregma $+3.20 \mathrm{~mm}$ ) showing the location of stimulating electrodes in $\mathrm{PrCm}, \mathrm{ACd}, \mathrm{PL}$, and IL. (C) A brief train of pulses was delivered to $\mathrm{PrCm}, \mathrm{ACd}$, PL, or IL 100-400 msec after tone onset on Day 2, in order to simulate tone responses.

lation was 100-400 msec after tone onset, which corresponds to the latency of naturally occurring tone responses in these areas (Peterson 1986; Yajeya et al. 1988; Baeg et al. 2001; Milad and Quirk 2002). As shown in Figure 2A,B, microstimulation of PrCm and ACd had no effect on the expression of freezing during extinction training. A repeated measures ANOVA performed on the extinction data showed no difference between stimulated and unstimulated groups for $\operatorname{PrCm}\left(F_{(1,12)}=0.003 ; P=0.96\right.$; see Fig. $2 \mathrm{~A})$ or ACd $\left(F_{(1,14)}=0.10 ; P=0.75\right.$; see Fig. $\left.2 \mathrm{~B}\right)$. On Day 3 , in the absence of microstimulation, there was also no difference between groups in either structure (PrCm: 67\% freezing; Unstim: $60 \%$ freezing; $t_{(18)}=0.73 ; P=0.48$; ACd: $44 \%$; Unstim: $44 \%$; $t_{(14)}=0.009 ; P=0.99$ ). Recovery of freezing on Day 3 (a measure of extinction recall) also did not differ between groups in $\mathrm{PrCm}$ $\left(t_{(18)}=0.60 ; P=0.55\right)$ and ACd $\left(t_{(14)}=0.40 ; P=0.69\right)$. Thus, microstimulation of PrCm and ACd had no observable effects on expression or extinction of conditioned fear.

\section{Microstimulation of PL impairs extinction}

In contrast to PrCm and ACd, microstimulation of PL impaired extinction. As shown in Figure 2C, rats receiving PL microstimulation showed a slower rate of extinction. A repeated measures ANOVA of the extinction data showed a trend toward an effect of group $\left(F_{(1,18)}=3.08, P=0.096\right)$. The following day, in the absence of stimulation, freezing in PL-stimulated rats (69\%) was significantly higher than the Unstim group $\left(40 \% ; t_{(18)}=2.53\right.$, $P=0.02$ ). In fact, PL-stimulated rats recovered $93 \%$ of their acquired freezing, compared with only $48 \%$ in the Unstim group $\left(t_{(18)}=3.04, P=0.007\right.$; Fig. $\left.2 \mathrm{C}\right)$, suggesting that PL microstimulation prevented extinction learning.

To facilitate between-structure comparisons, IL-stimulation data from our previously published study (Milad et al. 2004) are reproduced in Figure 2D. Repeated measures ANOVA of these data showed a significant effect of treatment $\left(F_{(1,19)}=13.28\right.$, $P=0.0017)$ and trial block $\left(F_{(1,19)}=41.47, P<0.001\right)$. The following day, in the absence of stimulation, IL rats froze significantly less than the Unstim group ( $30 \%$ vs. $\left.62 \% ; t_{(19)}=2.52, P=0.02\right)$. Recovery of freezing on Day 3 was $41 \%$ in IL-stimulated rats, compared with $79 \%$ in the Unstim group $\left(t_{(19)}=2.83, P=0.01\right)$. Thus, in the previous study, IL stimulation decreased the expression of conditioned freezing and strengthened extinction learning (Milad et al. 2004).

\section{Microstimulation of PL and IL has opposite effects on fear expression and extinction.}

The above experiments suggest that microstimulation of PL and IL has opposite effects on the expression of conditioned fear.

A

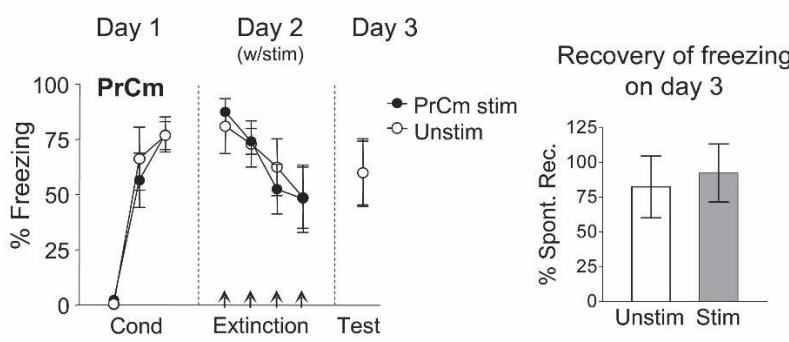

B

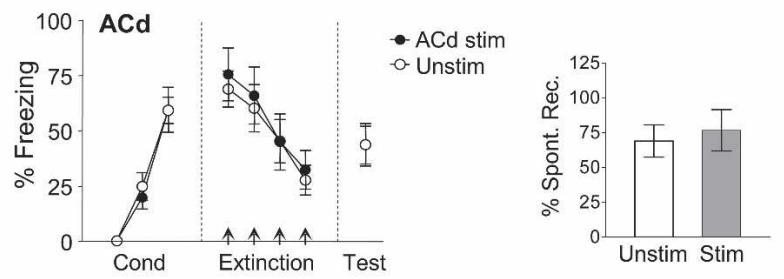

C
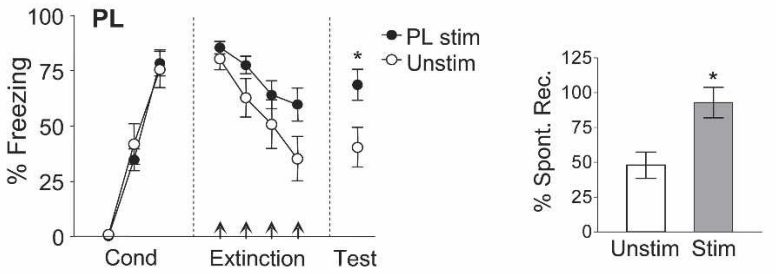

D
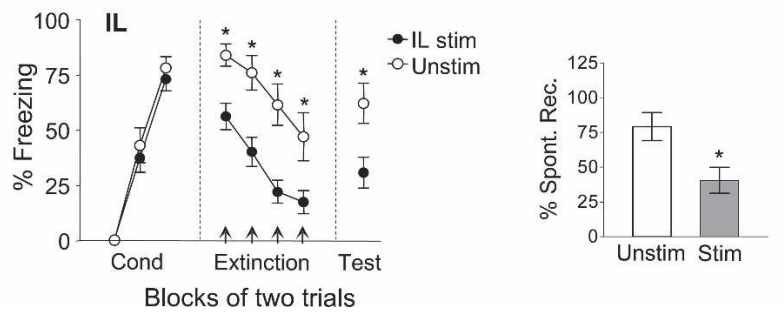

Figure 2. $\mathrm{PL}$ microstimulation, but not $\mathrm{PrCm}$ or $\mathrm{ACd}$, impairs extinction. (A) Microstimulation of $\operatorname{PrCm}(n=7)$ or $(B) \operatorname{ACd}(n=7)$ on Day 2 had no effect on acquisition of extinction or subsequent retrieval of extinction (Day 3) when compared with Unstim group ( $n=7 ; n=9$, respectively). (C) PL microstimulation $(n=11)$ showed a trend of having a slower rate of extinction on Day 2 when compared with Unstim group $(n=9 ; P=0.09)$. Furthermore, animals that received PL microstimulation on Day 2 had significantly greater recovery of freezing when compared with the Unstim group (Figs. in the right; $P<0.01$ ). (D) IL microstimulation data from Milad et al. (2004) is shown for comparison purposes. 
A
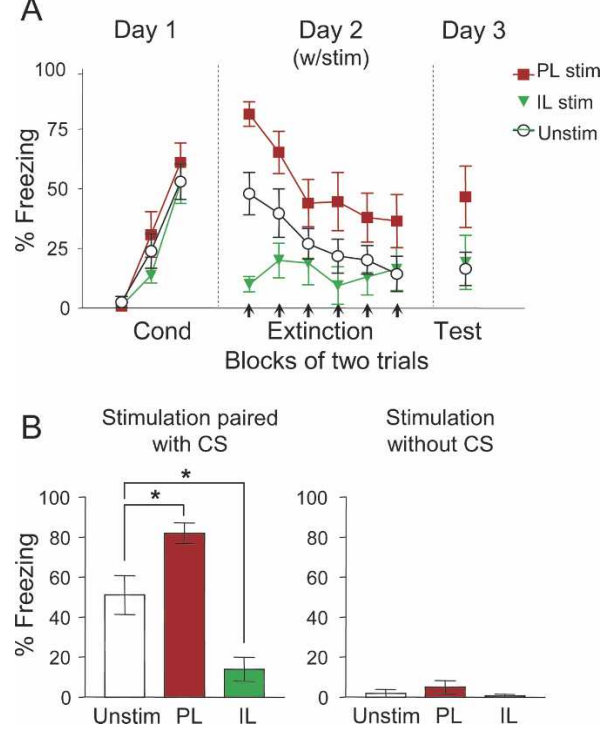

Figure 3. Under low footshock conditions, PL microstimulation increases fear expression, whereas IL microstimulation decreases fear expression. (A) On Day 2, PL microstimulation $(n=8)$ increased conditioned freezing whereas IL microstimulation $(n=6)$ decreased freezing, compared with the Unstim group $(n=12)$. On Day 3, there was no significant difference between groups (ANOVA, $P=0.08)$. ( $B$, left) Bar graph showing percent freezing for the very first extinction trial on Day 2 (one-way ANOVA $P<0.001$; Unstim vs. IL: $P=0.020$; Unstim vs. $\mathrm{PL}$ : $P=0.036$; IL vs. PL: $P<0.001$ ). (Right) Microstimulation delivered in the absence of conditioned tone had no effect. $\mathrm{CS}=$ conditioned stimulus (tone).

However, due to ceiling levels of freezing at the start of extinction, it was not possible to determine whether PL microstimulation augmented fear expression, independent of any effect on extinction. To address this question, we repeated the IL and PL stimulation in a separate experiment using a lower footshock intensity ( $0.3 \mathrm{~mA}$ instead of $0.5 \mathrm{~mA})$. Under these conditions, PL microstimulation significantly increased conditioned freezing from the start of the extinction phase (see Fig. 3A). In the first extinction trial, freezing levels were $82 \%, 14 \%$, and $51 \%$ for PLstimulated, IL-stimulated, and Unstim groups, respectively (see Fig. 3B, left). One-way ANOVA revealed a significant effect of group $\left(F_{(2,23)}=12.26 ; P<0.001\right)$ and post hoc analyses confirmed that both PL-stimulated and IL-stimulated animals differed significantly from Unstim animals (Unstim vs. IL: $P=0.020$; Unstim vs. PL: $P=0.036$; IL vs. PL: $P<0.001)$, confirming that PL and IL stimulation had opposite effects on conditioned freezing.

On Day 3, in the absence of microstimulation, PL, IL, and Unstim animals froze $47 \%, 19 \%$, and $17 \%$, respectively (see Fig. 3A). One-way ANOVA showed a trend toward an effect of group, which did not reach significance $\left(F_{(2,23)}=2.82, P=0.080\right)$. In contrast to our previous studies (Milad and Quirk 2002; Milad et al. 2004), we did not observe facilitation of the extinction memory in IL-stimulated animals. This is likely due to a floor effect in freezing under low footshock conditions. Microstimulation of PL and IL had no effect on freezing if administered in the absence of the tone (Fig. $3 \mathrm{~B}$, left, $F_{(2,22)}=0.71, P=0.50$ ), suggesting that microstimulation does not induce spontaneous freezing, but instead modulates freezing elicited by the tone.

\section{Discussion}

In this study, we paired microstimulation with conditioned tones to determine the impact of tone-evoked activity in MPFC subregions on fear expression and extinction. We observed that PL microstimulation increased conditioned freezing and impaired extinction. IL microstimulation had the opposite effect, decreasing conditioned freezing and, under standard footshock conditions (Milad and Quirk 2002; Milad et al. 2004), facilitating extinction. In contrast, microstimulation of ACd and PrCm had no effect on either fear expression or extinction. These findings suggest that tone responses in different prefrontal subregions differentially affect fear behavior.

The opposite effects of PL and IL microstimulation suggest that these mPFC subterritories target different brain regions important for fear expression. PL projects robustly to the basal nucleus of the amygdala (BA) (see Fig. 4; Buchanan et al. 1994; McDonald et al. 1996; Vertes 2004). This projection is thought to be excitatory based on anatomical (Brinley-Reed et al. 1995) and physiological (Likhtik et al. 2005, but see Rosenkranz and Grace 2002) findings. The BA projects to output neurons of the medial part of the central nucleus of the amygdala (CeM) (Smith and Paré 1994; Paré et al. 1995; Pitkanen et al. 1995). These projections are excitatory (Quirk et al. 2003), causing CeM output neurons to trigger midbrain and hypothalamic structures responsible for generating fear responses (LeDoux et al. 1988; De Oca et al. 1998). While the BA was thought not to be involved in expression of conditioned freezing based on pre-training lesions (Goosens and Maren 2001; Nader et al. 2001; Sotres-Bayon et al. 2004), we recently showed that post-training lesions of BA abolish the expression of previously acquired fear memories (AngladaFigueroa and Quirk 2005). Thus, excitatory projections from PL to BA could be responsible for the increased freezing caused by PL microstimulation. An alternative explanation is that PL inhibits IL, thereby disinhibiting fear outputs (see arrow in Fig. 4). Impaired extinction by PL microstimulation could be caused by potentiation of PL-BA circuits, resulting in a failure to recall extinction memory learned the previous day.

IL, on the other hand, does not project to BA, but instead projects to GABAergic cells in the lateral subdivision of the central nucleus (CeL) and intercalated (ITC) cell masses of the amygdala (Cassell and Wright 1986; Sesack et al. 1989; Hurley et al. 1991; McDonald et al. 1996; Freedman et al. 2000; Vertes 2004). These GABAergic cells have been shown to exert inhibitory control over CeM output neurons (Royer et al. 1999). Thus, as previously suggested (Royer and Paré 2002; Quirk et al. 2003; Milad et al. 2004; Paré et al. 2004), IL may inhibit fear via the CeL/ITC cell groups. In support of this, electrical stimulation of IL inhibits the responsiveness of Ce neurons to BA stimulation (Quirk et al. 2003) and chemical stimulation of IL increased c-Fos labeling in amygdala ITC cells (Berretta et al. 2005). Thus, the differential

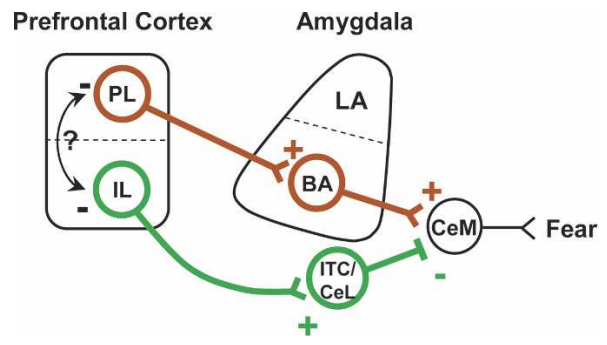

Figure 4. Model of prelimbic (PL) and infralimbic (IL) interactions with the amygdala. During PL microstimulation, feedforward excitation activates (plus sign) the basal amygdala (BA) which in turn activates the medial division of the central nucleus (CeM) to produce conditioned fear responses. In contrast, IL microstimulation excites GABAergic cells in the intercalated (ITC) region as well as the lateral division of the central nucleus (CeL). Excitation of both of these nuclei inhibits (minus sign) the output of CeM and reduces fear. Future experiments will determine if local inhibitory interactions between PL and IL (arrow) are important for controlling fear expression. 
projections of PL and IL to the amygdala may allow these structures to increase and decrease, respectively, the expression of conditioned fear. Moreover, the high frequency stimulation we used likely potentiated local circuitry within the mPFC (Herry and Garcia 2002), mPFC targets in BA, or mPFC targets in ITC (Royer and Paré 2002). Plasticity in these sites could explain the enduring effects of microstimulation that we observed.

Microstimulation of PrCm and ACd had no effect on expression or extinction of conditioned freezing, suggesting that targets of these areas differ from those of PL and IL. Unlike PL and IL, PrCm and ACd project weakly to the amygdala (Sesack et al. 1989; Hurley et al. 1991) and ventrolateral periaqueductal gray (Floyd et al. 2000; Gabbott et al. 2005), structures critical for expression of freezing (De Oca et al. 1998). Previous studies have demonstrated tone-evoked responses during fear conditioning and extinction in PrCm and ACd (Peterson 1986; Yajeya et al. 1988; Barrett et al. 2003). Given the robust projections of PrCm and ACd to the dorsal striatum and intralaminar thalamic nuclei (Heidbreder and Groenewegen 2003; Gabbott et al. 2005), toneevoked activity in PrCm and ACd might be important for avoidance and attentional processes related to fear (Heidbreder and Groenewegen 2003; Malin and McGaugh 2006). However, lesions of ACd have been shown to increase freezing behavior (Morgan and LeDoux 1995; Vouimba et al. 2000), suggesting that this structure may be responsible for tonic inhibition of fear.

Recent studies support the idea that PL and IL have opposite effects on fear expression and extinction. Lesions restricted to IL impair recall of extinction (Quirk et al. 2000; Lebron et al. 2004), causing increased freezing at test. Similarly, infusing antagonists of NMDA receptors (Burgos-Robles et al. 2004), MAP kinase inhibitors (Hugues et al. 2004, 2006), or protein synthesis inhibitors (Santini et al. 2004) into IL impairs subsequent recall of extinction. These findings suggest that potentiation of IL inputs during extinction is necessary for suppressing fear during recall of extinction. Consistent with this, IL neurons do not signal conditioning, but signal extinction recall (Milad and Quirk 2002; Barrett et al. 2003). Recent lesion studies, however, have reported that $\mathrm{mPFC}$ lesions have no effect on fear extinction (Farinelli et al. 2006; Garcia et al. 2006). Lesions in those studies damaged both IL and PL and, in light of the opposite effects on freezing reported here, might be expected to have no net effect. In contrast to IL, PL lesions (Joel et al. 1997) and mPFC inactivation (including PL) reduce the expression of conditioned fear (Akirav et al. 2006; Blum et al. 2006; Sierra-Mercado et al. 2006). Finally, in support of opposite roles of IL and PL in fear expression, Gilmartin and McEchron (2005) recently observed that IL and PL neurons respond in an opposite manner to conditioned tones.

Recently, there has been a surge of interest in the neurobiology of fear conditioning and extinction in humans, reflecting prevailing theories that these processes may be critical to the pathophysiology of anxiety disorders as well as their treatment by extinction-based behavioral therapies (Milad et al. 2006; Rauch et al. 2006). Pertinent to our present findings, deep brain stimulation and transcranial magnetic stimulation have shown promise as treatments for mood and anxiety disorders (George and Belmaker 2000; Greenberg and Rezai 2003; Nuttin et al. 2003). The advancement of neurostimulation therapies requires a sophisticated understanding of the mediating neuroanatomy. Neuroimaging studies have already begun to establish the human homologs of IL in the ventromedial prefrontal loci, which show structural and functional correlations with extinction recall (Phelps et al. 2004; Milad et al. 2005). Our findings suggest that identifying a human homolog of PL, responsible for impeding extinction processes, might be of comparable importance. Inhibiting the function of the PL homolog via neurostimulation methods in humans could represent a viable means of facilitating extinction, as a treatment for anxiety disorders.

In summary, we have demonstrated that there are separate modules within the mPFC that differentially affect fear expression in rats. Microstimulation findings suggest that tone-induced activity in PL increases fear expression and impairs extinction, while tone-induced activity in IL has the opposite effect. This suggests that mPFC is not functionally monolithic, but contains discrete subregions that differentially regulate fear behavior. Identification of homologous prefrontal subregions in rats and humans, and their respective roles in fear conditioning and extinction, will be needed to adequately translate rodent findings in order to advance human therapeutics.

\section{Materials and Methods}

\section{Subjects}

All experiments were approved by the Institutional Animal Care and Use Committee of the Ponce School of Medicine in compliance with the National Institutes of Health guidelines for the care and use of laboratory animals. Three-month-old male SpragueDawley rats weighing $\sim 300$ g were housed individually in transparent polyethylene cages located in a negative pressure clean room (Colorado Clean Room) and maintained on a 12-h light/ 12-h dark schedule with free access to water. Rats were foodrestricted until they reached $85 \%$ of their control body weight, at which time they were trained to press a bar for food pellets on a variable interval schedule of reinforcement with food available approximately every $60 \mathrm{sec}$. Bar-press training was used to maintain a constant level of activity against which freezing responses could be reliably measured during long sessions (Quirk et al. 2000). After reaching a criterion of $\sim 15$ presses/min, rats were implanted with stimulating electrodes.

\section{Surgery}

Rats were anesthetized with ketamine (90 mg/kg, i.p.) and xylazine $(10 \mathrm{mg} / \mathrm{kg}$, i.p.) and placed into a stereotaxic apparatus (David Kopf Instruments). Supplemental doses of ketamine were given as needed to maintain a deep level of anesthesia, as indicated by a slow respiratory rate and lack of response to tail pinch. After leveling the scalp such that lambda and bregma were in the same horizontal plane, a burr hole was drilled over the right mPFC with a dental drill. Three additional burr holes were drilled for anchoring screws. A stimulating electrode (see below) was implanted unilaterally in one of four structures: PrCm, ACd, PL, or IL. Stereotaxic coordinates relative to bregma were as follows: PrCm: $3.7 \mathrm{~mm}$ anterior, $1.6 \mathrm{~mm}$ lateral, $2.2 \mathrm{~mm}$ ventral; ACd: 2.9 $\mathrm{mm}$ anterior, $1.0 \mathrm{~mm}$ lateral, $2.6 \mathrm{~mm}$ ventral; PL: $2.9 \mathrm{~mm}$ anterior, $1.0 \mathrm{~mm}$ lateral, $4.2 \mathrm{~mm}$ ventral; and IL: $2.9 \mathrm{~mm}$ anterior, 1.0 $\mathrm{mm}$ lateral, $5.0 \mathrm{~mm}$ ventral. Electrodes were angled $6^{\circ}$ toward the midline. Rats were implanted unilaterally (right) as previously described (Milad and Quirk 2002; Milad et al. 2004). Tracing studies have shown that PL and IL axons project bilaterally to subcortical structures such as the amygdala (McDonald et al. 1996; Vertes 2004). Therefore, unilateral PFC microstimulation likely affects subcortical structures bilaterally. Electrodes were cemented to the skull with dental acrylic and the incision was sutured. At the conclusion of the experiment, the tip of the electrode was marked by passing a $25 \mu \mathrm{A}$ anodal current for $18 \mathrm{sec}$. The location of electrodes was reconstructed with standard histological techniques from Nissl-stained sections.

\section{Fear conditioning}

Rats were fear conditioned and extinguished in the same chamber in which they received bar-press training. The conditioned stimulus (CS) was a $30-\mathrm{sec}, 4-\mathrm{kHz}$ tone, with an intensity of 75 $\mathrm{dB}$. The intervals between tone presentations averaged $4 \mathrm{~min}$ (range: 2-6 min). The unconditioned stimulus (US) was a scrambled footshock, $0.5 \mathrm{sec}$ in duration, which coterminated with the tone. The intensity of the footshock was $0.5 \mathrm{~mA}$ (Ex- 
periment 1) or $0.3 \mathrm{~mA}$ (Experiment 2). The experiment took place over 3 d. On Day 1, rats received five tone-alone trials (habituation phase) immediately followed by five CS-US trials (conditioning phase) and groups. Rats that did not meet minimum criteria for acquisition of conditioned freezing ( $>20 \%$ freezing in the last trial block of conditioning) were excluded. On Day 2 , rats were returned to the same operant chamber and were given partial extinction training (eight trials, Experiment 1) or complete extinction (12 trials, Experiment 2). Extinction tones on Day 2 were paired with microstimulation to the mPFC (Stim group) or were given alone (Unstim group). For comparison issues, microstimulation of IL data presented in Experiment 1 was adapted from Milad et al. (2004) (Fig. 2D). On Day 3, all rats were given two extinction trials in the absence of microstimulation to test for any lasting effects of stimulation on extinction memory.

\section{Microstimulation}

Microstimulation was delivered through a concentric bipolar electrode (SNE-100, Rhodes Medical Instruments) with the center contact protruding from the annular contact by $1.0 \mathrm{~mm}$. A stimulator (S48 stimulator; Grass Instruments) generated square pulses, $0.2 \mathrm{msec}$ in duration, at a frequency of $100 \mathrm{~Hz}$. Stimulation was delivered $100-400 \mathrm{msec}$ after tone onset (total 30 pulses), which corresponds to the latency of naturally occurring conditioned tone responses in PrCm (Yajeya et al. 1988), ACd (Peterson 1986), PL (Baeg et al. 2001), and IL (Milad and Quirk 2002). The output of the stimulator was connected to a constant current output (Grass Instruments) which maintained current at $100 \mu \mathrm{A}$.

\section{Data analysis}

Freezing, defined as the cessation of all movements other than respiration, was used as the measure of conditioned fear (Blanchard and Blanchard 1972). The total time-spent freezing during each 30 -sec tone presentation was scored from videotapes by a blind observer. Freezing values were examined using repeated measures analyses of variance (ANOVA), and post hoc comparisons were made by using Tukey-HSD test (Statistica; StatSoft). Retrieval of extinction on Day 3 was measured as recovery of freezing, calculated as the freezing expressed in the first trial block on Day 3, divided by the last trial block of conditioning on Day 1 . Recovery values were compared using two-tailed $t$-test.

\section{Acknowledgments}

We thank Dr. Mohammed R. Milad and Dr. Denis Paré for comments on the manuscript. This study was supported by NIH grants MH058883 and GM008239 to GJQ, MH072156 to SLR, an American Psychological Association Diversity Program in Neuroscience pre-doctoral fellowship to IVG and a Puerto Rico Louis Stokes Alliance for Minority Participation fellowship to BVG.

\section{In Memoriam}

This study is dedicated to the memory of the first author, Ivan Vidal-Gonzalez, who passed away on August 25, 2006. He was in the final year of his doctoral work. This proud son of Ponce will be missed by many, both inside and outside Puerto Rico.

\section{References}

Akirav, I., Raizel, H., and Maroun, M. 2006. Enhancement of conditioned fear extinction by infusion of the GABA agonist muscimol into the rat prefrontal cortex and amygdala. Eur. J. Neurosci. 23: 758-764.

Amat, J., Baratta, M.V., Paul, E., Bland, S.T., Watkins, L.R., and Maier, S.F. 2005. Medial prefrontal cortex determines how stressor controllability affects behavior and dorsal raphe nucleus. Nat. Neurosci. 8: 365-371.

Anglada-Figueroa, D. and Quirk, G.J. 2005. Lesions of the basal amygdala block expression of conditioned fear but not extinction. $J$. Neurosci. 25: 9680-9685.

Baeg, E.H., Kim, Y.B., Jang, J., Kim, H.T., Mook-Jung, I., and Jung, M.W. 2001. Fast spiking and regular spiking neural correlates of fear conditioning in the medial prefrontal cortex of the rat. Cereb. Cortex
11: $441-451$.

Barrett, D., Shumake, J., Jones, D., and Gonzalez-Lima, F. 2003. Metabolic mapping of mouse brain activity after extinction of a conditioned emotional response. J. Neurosci. 23: 5740-5749.

Berretta, S., Pantazopoulos, H., Caldera, M., Pantazopoulos, P., and Paré, D. 2005. Infralimbic cortex activation increases c-Fos expression in intercalated neurons of the amygdala. Neuroscience 132: 943-953.

Blanchard, D.C. and Blanchard, R.J. 1972. Innate and conditioned reactions to threat in rats with amygdaloid lesions. J. Comp. Physiol. Psychol. 81: 281-290.

Blum, S., Hebert, A.E., and Dash, P.K. 2006. A role for the prefrontal cortex in recall of recent and remote memories. Neuroreport 17: $341-344$.

Brinley-Reed, M., Mascagni, F., and McDonald, A.J. 1995. Synaptology of prefrontal cortical projections to the basolateral amygdala: An electron microscopic study in the rat. Neurosci. Lett. 202: 45-48.

Buchanan, S.L., Thompson, R.H., Maxwell, B.L., and Powell, D.A. 1994. Efferent connections of the medial prefrontal cortex in the rabbit. Exp. Brain Res. 100: 469-483.

Burgos-Robles, A., Santini, E., and Quirk, G.J. 2004. Blockade of NMDA receptors in the medial prefrontal cortex impairs consolidation of fear extinction. Abstract Viewer/Itinerary Planner, Program No. 328.14. Society for Neuroscience, Washington, D.C.

Burgos-Robles, A., Vidal-Gonzalez, I., and Quirk, G.J. 2005. Systemic blockade of NMDA receptors with CPP does not alter firing rate or bursting of medial prefrontal cortex neurons. Abstract Viewer/Itinerary Planner, Program No. 539.9. Society for Neuroscience, Washington, D.C.

Cassell, M.D. and Wright, D.J. 1986. Topography of projections from the medial prefrontal cortex to the amygdala in the rat. Brain Res. Bull. 17: 321-333.

De Oca, B.M., DeCola, J.P., Maren, S., and Fanselow, M.S. 1998. Distinct regions of the periaqueductal gray are involved in the acquisition and expression of defensive responses. J. Neurosci. 18: 3426-3432.

Farinelli, M., Deschaux, O., Hugues, S., Thevenet, A., and Garcia, R. 2006. Hippocampal train stimulation modulates recall of fear extinction independently of prefrontal cortex synaptic plasticity and lesions. Learn. Mem. 13: 329-334.

Floyd, N.S., Price, J.L., Ferry, A.T., Keay, K.A., and Bandler, R. 2000. Orbitomedial prefrontal cortical projections to distinct longitudinal columns of the periaqueductal gray in the rat. J. Comp. Neurol. 422: $556-578$.

Freedman, L.J., Insel, T.R., and Smith, Y. 2000. Subcortical projections of area 25 (subgenual cortex) of the macaque monkey. J. Comp. Neurol. 421: $172-188$.

Gabbott, P.L., Warner, T.A., Jays, P.R., Salway, P., and Busby, S.J. 2005. Prefrontal cortex in the rat: Projections to subcortical autonomic, motor, and limbic centers. J. Comp. Neurol. 492: 145-177.

Garcia, R., Chang, C.H., and Maren, S. 2006. Electrolytic lesions of the medial prefrontal cortex do not interfere with long-term memory of extinction of conditioned fear. Learn. Mem. 13: 14-17.

George, M.S. and Belmaker, R. 2000. Transcranial magnetic stimulation in neuropsychiatry. American Psychiatric Press, Washington, D.C.

Gilmartin, M.R. and McEchron, M.D. 2005. Single neurons in the medial prefrontal cortex of the rat exhibit tonic and phasic coding during trace fear conditioning. Behav. Neurosci. 119: 1496-1510.

Goosens, K.A. and Maren, S. 2001. Contextual and auditory fear conditioning are mediated by the lateral, basal, and central amygdaloid nuclei in rats. Learn. Mem. 8: 148-155.

Greenberg, B.D. and Rezai, A.R. 2003. Mechanisms and the current state of deep brain stimulation in neuropsychiatry. CNS Spectr. 8: $522-526$.

Heidbreder, C.A. and Groenewegen, H.J. 2003. The medial prefrontal cortex in the rat: Evidence for a dorso-ventral distinction based upon functional and anatomical characteristics. Neurosci. Biobehav. Rev. 27: 555-579.

Herry, C. and Garcia, R. 2002. Prefrontal cortex long-term potentiation, but not long-term depression, is associated with the maintenance of extinction of learned fear in mice. J. Neurosci. 22: 577-583.

Hugues, S., Deschaux, O., and Garcia, R. 2004. Postextinction infusion of a mitogen-activated protein kinase inhibitor into the medial prefrontal cortex impairs memory of the extinction of conditioned fear. Learn. Mem. 11: 540-543.

Hugues, S., Chessel, A., Lena, I., Marsault, R., and Garcia, R. 2006. Prefrontal infusion of PD098059 immediately after fear extinction training blocks extinction-associated prefrontal synaptic plasticity and decreases prefrontal ERK2 phosphorylation. Synapse 60: $280-287$.

Hurley, K.M., Herbert, H., Moga, M.M., and Saper, C.B. 1991. Efferent projections of the infralimbic cortex of the rat. J. Comp. Neurol. 308: $249-276$.

Joel, D., Tarrasch, R., Feldon, J., and Weiner, I. 1997. Effects of

\section{Learning \& Memory}


electrolytic lesions of the medial prefrontal cortex or its subfields on 4-arm baited, 8-arm radial maze, two-way active avoidance and conditioned fear tasks in the rat. Brain Res. 765: 37-50.

Lebron, K., Milad, M.R., and Quirk, G.J. 2004. Delayed recall of fear extinction in rats with lesions of ventral medial prefrontal cortex. Learn. Mem. 11: 544-548.

LeDoux, J.E., Iwata, J., Cicchetti, P., and Reis, D.J. 1988. Different projections of the central amygdaloid nucleus mediate autonomic and behavioral correlates of conditioned fear. J. Neurosci. 8: $2517-2529$.

Likhtik, E., Pelletier, J.G., Paz, R., and Paré, D. 2005. Prefrontal control of the amygdala. J. Neurosci. 25: 7429-7437.

Malin, E.L. and McGaugh, J.L. 2006. Differential involvement of the hippocampus, anterior cingulate cortex, and basolateral amygdala in memory for context and footshock. Proc. Natl. Acad. Sci. 103: $1959-1963$.

McDonald, A.J., Mascagni, F., and Guo, L. 1996. Projections of the medial and lateral prefrontal cortices to the amygdala: A Phaseolus vulgaris leucoagglutinin study in the rat. Neuroscience 71: 55-75.

Milad, M.R. and Quirk, G.J. 2002. Neurons in medial prefrontal cortex signal memory for fear extinction. Nature 420: 70-74.

Milad, M.R., Vidal-Gonzalez, I., and Quirk, G.J. 2004. Electrical stimulation of medial prefrontal cortex reduces conditioned fear in a temporally specific manner. Behav. Neurosci. 118: 389-395.

Milad, M.R., Quinn, B.T., Pitman, R.K., Orr, S.P., Fischl, B., and Rauch, S.L. 2005. Thickness of ventromedial prefrontal cortex in humans is correlated with extinction memory. Proc. Natl. Acad. Sci. 102: 10706-10711.

Milad, M.R., Rauch, S.L., Pitman, R.K., and Quirk, G.J. 2006. Fear extinction in rats: Implications for human brain imaging and anxiety disorders. Biol. Psychol. 73: 61-71.

Morgan, M.A. and LeDoux, J.E. 1995. Differential contribution of dorsal and ventral medial prefrontal cortex to the acquisition and extinction of conditioned fear in rats. Behav. Neurosci. 109: 681-688.

Nader, K., Majidishad, P., Amorapanth, P., and LeDoux, J.E. 2001. Damage to the lateral and central, but not other, amygdaloid nuclei prevents the acquisition of auditory fear conditioning. Learn. Mem. 8: $156-163$.

Nuttin, B.J., Gabriels, L.A., Cosyns, P.R., Meyerson, B.A., Andreewitch, S., Sunaert, S.G., Maes, A.F., Dupont, P.J., Gybels, J.M., Gielen, F., et al. 2003. Long-term electrical capsular stimulation in patients with obsessive-compulsive disorder. Neurosurgery 52: 1263-1272.

Paré, D., Smith, Y., and Paré, J.F. 1995. Intra-amygdaloid projections of the basolateral and basomedial nuclei in the cat: Phaseolus vulgaris-leucoagglutinin anterograde tracing at the light and electron microscopic level. Neuroscience 69: 567-583.

Paré, D., Quirk, G.J., and LeDoux, J.E. 2004. New vistas on amygdala networks in conditioned fear. J. Neurophysiol. 92: 1-9.

Pelletier, J.G. and Paré, D. 2004. Role of amygdala oscillations in the consolidation of emotional memories. Biol. Psychiatry 55: 559-562.

Peterson, S.L. 1986. Prefrontal cortex neuron activity during a discriminative conditioning paradigm in unanesthetized rats. Int. J. Neurosci. 29: 245-254.

Phelps, E.A., Delgado, M.R., Nearing, K.I., and LeDoux, J.E. 2004 Extinction learning in humans: Role of the amygdala and vmPFC. Neuron 43: 897-905.

Pitkanen, A., Stefanacci, L., Farb, C.R., Go, G.G., LeDoux, J.E., and Amaral, D.G. 1995. Intrinsic connections of the rat amygdaloid complex: Projections originating in the lateral nucleus. J. Comp. Neurol. 356: 288-310.

Quirk, G.J., Russo, G.K., Barron, J.L., and Lebron, K. 2000. The role of ventromedial prefrontal cortex in the recovery of extinguished fear. J. Neurosci. 20: 6225-6231.

Quirk, G.J., Likhtik, E., Pelletier, J.G., and Paré, D. 2003. Stimulation of medial prefrontal cortex decreases the responsiveness of central amygdala output neurons. J. Neurosci. 23: 8800-8807.

Quirk, G.J., Garcia, R., and Gonzalez-Lima, F. 2006. Prefrontal mechanisms in extinction of conditioned fear. Biol. Psychiatry 60: $337-343$.

Rauch, S.L., Shin, L.M., and Phelps, E.A. 2006. Neurocircuitry models of posttraumatic stress disorder and extinction: Human neuroimaging research-past, present, and future. Biol. Psychiatry 60: 376-382.

Rosenkranz, J.A. and Grace, A.A. 2002. Cellular mechanisms of infralimbic and prelimbic prefrontal cortical inhibition and dopaminergic modulation of basolateral amygdala neurons in vivo. J. Neurosci. 22: 324-337.

Rosenkranz, J.A., Moore, H., and Grace, A.A. 2003. The prefrontal cortex regulates lateral amygdala neuronal plasticity and responses to previously conditioned stimuli. I. Neurosci. 23: 11054-11064.

Royer, S. and Paré, D. 2002. Bidirectional synaptic plasticity in intercalated amygdala neurons and the extinction of conditioned fear responses. Neuroscience 115: 455-462.

Royer, S., Martina, M., and Paré, D. 1999. An inhibitory interface gates impulse traffic between the input and output stations of the amygdala. J. Neurosci. 19: 10575-10583.

Santini, E., Ge, H., Ren, K., Pena, D.O., and Quirk, G.J. 2004 Consolidation of fear extinction requires protein synthesis in the medial prefrontal cortex. J. Neurosci. 24: 5704-5710.

Sesack, S.R., Deutch, A.Y., Roth, R.H., and Bunney, B.S. 1989. Topographical organization of the efferent projections of the medial prefrontal cortex in the rat: An anterograde tract-tracing study with Phaseolus vulgaris leucoagglutinin. J. Comp. Neurol. 290: 213-242.

Sierra-Mercado, D., Corcoran, K.A., Lebron-Milad, K., and Quirk, G.J. 2006. Inactivation of ventromedial prefrontal cortex reduces expression of conditioned fear and impairs subsequent recall of extinction. Eur. J. Neurosci. 24: 1751-1758.

Smith, Y. and Paré, D. 1994. Intra-amygdaloid projections of the lateral nucleus in the cat: PHA-L anterograde labeling combined with postembedding GABA and glutamate immunocytochemistry. $J$. Comp. Neurol. 342: 232-248.

Sotres-Bayon, F., Bush, D.E., and LeDoux, J.E. 2004. Emotional perseveration: An update on prefrontal-amygdala interactions in fear extinction. Learn. Mem. 11: 525-535.

Vertes, R.P. 2004. Differential projections of the infralimbic and prelimbic cortex in the rat. Synapse 51: 32-58.

Vouimba, R.M., Garcia, R., Baudry, M., and Thompson, R.F. 2000. Potentiation of conditioned freezing following dorsomedial prefrontal cortex lesions does not interfere with fear reduction in mice. Behav. Neurosci. 114: 720-724.

Yajeya, J., Quintana, J., and Fuster, J.M. 1988. Prefrontal representation of stimulus attributes during delay tasks. II. The role of behavioral significance. Brain Res. 474: 222-230.

Received May 2, 2006; accepted in revised form September 22, 2006. 


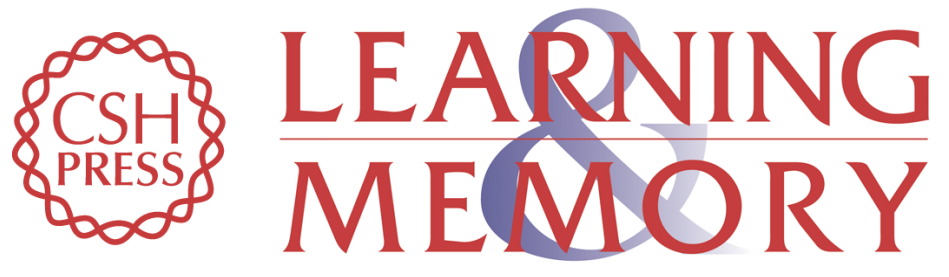

\section{Microstimulation reveals opposing influences of prelimbic and infralimbic cortex on the expression of conditioned fear}

Ivan Vidal-Gonzalez, Benjamín Vidal-Gonzalez, Scott L. Rauch, et al.

Learn. Mem. 2006, 13:

Access the most recent version at doi:10.1101//m.306106

References This article cites 60 articles, 21 of which can be accessed free at:

http://learnmem.cshlp.org/content/13/6/728.full.html\#ref-list-1

License

Email Alerting Receive free email alerts when new articles cite this article - sign up in the box at the Service top right corner of the article or click here. 